BLS 32, No 2 2006. DOI: http://dx.doi.org/10.3765/bls.v32i2.3494

(published by the Berkeley Linguistics Society and the Linguistic Society of America)

\title{
On the Argument Structure of Complex Predicates in Kalam, a Language of the Trans New Guinea Family
}

\author{
ANDREW PAWLEY \\ Australian National University
}

\section{Introduction}

Complex predicates, characterized by having two or more heads, are problematic for models of language that assume a neat division of labor between syntax and lexicon (Alsina et al. 1997). On the one hand, such predicates usually have many of the properties of a typical lexical unit, for example in exhibiting a unified argument structure. On the other hand, syntactically the constituents of complex predicates function separately. Various theoretical frameworks have been applied in an effort to understand the workings of such constructions.

This paper examines argument structure in three construction types in Kalam, a language spoken around the junction of the Bismarck and Schrader Ranges in the southwest corner of Madang Province, Papua New Guinea. ${ }^{1}$ Kalam belongs to the Trans New Guinea (TNG) family, which with upwards of 400 members is by far the largest of the many 'Papuan' (non-Austronesian) families of Melanesia. Except for a branch in the Timor area, the Trans New Guinea family is confined to New Guinea and a few offshore islands.

The three types are serial verb constructions (SVCs), verb adjunct constructions (VACs), and involuntary (bodily or mental) experience constructions (IECs), each of which has analogs in many other TNG languages. Each construction contains, or has claims to contain, a complex predicate, but differs sharply from the other two in grammatical and semantic structure.

Serial verb constructions contain complex predicates that can have indefinitely many verb roots as heads. The main challenge here is to define what

\footnotetext{
${ }^{1}$ I am indebted to John Bowden and Mark Donohue for comments on drafts of this paper. My work on Kalam has been supported by grants from the Wenner-Gren Foundation for Anthropological Research, the New Zealand University Research Grants Committee, the Papua New Guinea Biological Foundation, and Amrad Discovery Technologies. I began working on Kalam as a graduate student more than 40 years ago, soon after the first government patrol post was established at Simbai. Other linguists who have worked on Kalam include Lyle and Helen Scholz of the Summer Institute of Linguistics, who spent 28 years based at Simbai, Bruce Biggs, Talmy Givón, and Jonathan Lane.
} 


\section{Andrew Pawley}

coreference and event structure constraints must apply to the arguments of different verbs before they can be combined in a single SVC. SVCs require a level of event structure semantics that refers to discourse structure wellformedness as well as to clause-internal constraints on argument structure.

Verb adjunct constructions depict a single event using two heads which belong to different parts of speech: verb and verb adjunct. The main questions here are: How do the argument structures of the two heads interact? What is the role of the verb adjunct? Is it a co-primary predicate, secondary predicate, or an incorporated argument of the verb? Do 'verb adjuncts' form a single and distinct part of speech, separate from nouns and adverbs?

There is a class of involuntary experience constructions which is transitive, requiring at least two nominal participants. One participant is an Experiencer, which is encoded as Direct Object. The other denotes a bodily or mental condition or process that affects the Experiencer. The main question here is: What is the grammatical status of the condition nominal? Is it the Subject, is it a kind of verb adjunct which adds to the meaning and argument structure of the verb, or is it in some strange way both Subject and verb adjunct?

My account of these three constructions will necessarily be brief and informal. In addition to constituent structure and semantic structure I will assume a distinction between two other levels of linguistic representation: argument structure (thematic arguments or macro-roles) and functional structure (grammatical functions such as subject and direct object), though I will in the usual way sometimes use 'argument structure' to refer to the whole domain in which thematic arguments are linked to grammatical functions. It is useful to distinguish between core arguments (roughly those conceptually central to a verb or construction, and which are usually expressed as complements) and peripheral arguments (not conceptually central and usually encoded as adjuncts).

Some leading Papuanists have been reluctant to attribute the grammatical functions Subject, Direct Object, and Indirect Object to Trans New Guinea languages or indeed to other Papuan families. Thus, in his influential book The Papuan Languages of New Guinea, William Foley (1986) does not use these terms at all. When talking about grammatical relations for 'core nominals', he refers only to semantic macro-roles, such as Actor, Undergoer, and Beneficiary.

Mark Donohue (2005) has recently argued that Subject is not usually a highly grammaticalized or well-defined category in Papuan languages of New Guinea. The entities that some Papuan grammars call Subjects are actually a conflation of constructs that belong to two different systems in the grammar:

(i) There are Logical Subjects, which belong to the semantics of the clause. 'Subject' is often applied to the NP that governs verbal agreement, the selection of actor suffixes on the verb. The verbal agreement system, Donohue says, can described without reference to 'Subject'. Instead, it is enough to refer to role prominence using a universal hierarchy of macroroles. (By implication, this applies also to 'Direct Object'.) 


\section{Argument Structure of Complex Predicates in Kalam}

(ii) There is the topical argument in a clause, a pragmatic or discourse-based construct. What is tracked by switch-reference morphology on the verb is typically the topic, not the most prominent macro-role. It happens that the two sometimes match, but they need not do so.

Donohue concludes (for most Papuan languages of New Guinea) that "clearly we do not find a constellation of syntactic phenomena each choosing the same grouping, and so lack any reason to postulate a notion of 'subject'" (2005:215)).

These arguments against the usefulness of recognising Subject and Object as opposed to ranking arguments on a universal hierarchy of thematic roles-and thus eliminating a level of functional grammatical relations-do not sit so well with Kalam. However, the Kalam data support Donohue on another point. There are certain constructions in $\mathrm{TNG}$ languages where it is difficult to determine subjecthood, in particular some involuntary experience constructions where the animate participant exerts no control over the event.

The merits of a lexicalist vs. a construction-based treatment of the argument structure of these kinds of predicate phrase will be touched on. In the lexicalist approach, argument structure is regarded as being inherent in the lexical verb. That is, a verb's array of thematic roles is defined by the meaning of the verb. Sense differences in a verb, including those that entail differences in the number and configuration of arguments, are attributed solely to polysemy in the verb and not to the different constructions in which it occurs.

I will suggest that, in the case of Kalam complex predicates, there are certain advantages in a construction-based treatment in the sense of Goldberg (1995). First, this allows for the two (or more) elements in a complex predicate to jointly determine the argument structure of the predicate. Second, allowing the construction as a whole as well as its lexical constituents to contribute to meaning, the polysemy of verbs in complex predicates can be constrained in an intuitively satisfying way.

The following abbreviations are used in glossing Kalam examples.

\begin{tabular}{|c|c|c|c|}
\hline $\begin{array}{l}\mathrm{D} \\
\mathrm{DS}\end{array}$ & $\begin{array}{l}\text { dual } \\
\text { different Subject (from following } \\
\text { verb) }\end{array}$ & PF & $\begin{array}{l}\text { perfect (denotes today's past, } \\
\text { present perfect or present- } \\
\text { iterative) }\end{array}$ \\
\hline DUR & durative & PAST.HAB & past habitual \\
\hline FUT & future & PRIOR & prior or preceding (the event \\
\hline HORT & hortative & & denoted by following verb) \\
\hline IMM & immediate past & PRES & present \\
\hline NDR & noun derivative suffix & PROG & present progressive \\
\hline OBJ & Object (case) & $\mathrm{S}$ & singular \\
\hline OPT & optative & SIM & simultaneous (with the event \\
\hline $\mathrm{P}$ & plural & & denoted by following verb) \\
\hline PAST & remote past (yesterday or earlier) & $\mathrm{SS}$ & same Subject (as following verb) \\
\hline
\end{tabular}

\section{Background Notes on Kalam Grammar}

Kalam has two main dialects, structurally very similar but with many differences 


\section{Andrew Pawley}

in morphological forms and lexicon. Some of the data cited here come from the Etp dialect of Kaironk and some from the Ti dialect of Gobnem, both spoken in the Upper Kaironk Valley. Unless otherwise stated, examples are from the Etp dialect.

\subsection{Word Classes}

The principal parts of speech are verbs, nouns, verb adjuncts, adjectives, and adverbs. Brief remarks on the first three follow. The last two will be discussed in $\S 3$.

Verb roots are a small, closed class with about 130 members. There are no processes for deriving new verb stems. However, polysemy roughly triples the number of sense units among verb roots. Verbs are the only part of speech to carry inflectional suffixes marking tense, aspect or mood, Subject person-andnumber, and switch reference (see $§ 1.3$ ). The small stock of verb roots is augmented by a large body of lexicalised complex predicates. Complex predicates make up between 25 and 30 percent of verbal predicates in text.

Nouns are a large class with many subclasses, including personal pronouns. There are two main sets of personal pronouns: the Subject (or nominative) set and Object (or accusative) set. The most basic forms in each set in the Etp dialect are given below.

$\begin{array}{llllllllll} & 1 \mathrm{~S} & 2 \mathrm{~S} & 3 \mathrm{~S} & 1 \mathrm{D} & 2 \mathrm{D} & 3 \mathrm{D} & 1 \mathrm{P} & 2 \mathrm{P} & 3 \mathrm{P} \\ \text { Subject } & y a d & n a d & n u k & c t & n t & \text { kikmay } & c n & n b & \text { kik } \\ \text { Object } & y p & n p & \text { nup } & \text { ctp } & \text { ntp } & \text { kipmay } & \text { cnp } & n b p & \text { kip }\end{array}$

Object pronouns are used both for canonical Direct Objects and for Indirect and Dative Objects. Possessive pronouns are drawn from one or the other of these sets according to whether the possessive phrase is the grammatical Subject or Object.

Verb adjuncts are roots or derived forms that occur only or primarily as the partner of one or a very few verb roots to form a complex predicate. The characteristics of this category will be described in more detail in $\S 3$.

\subsection{Verbal Clauses and Clause Sequencing}

A verbal clause consists minimally of an inflected verb. Many verb roots can take two core arguments. A few occur with three, e.g. ñ- 'give', yom- 'show', and taw'trade, buy, sell'. Locatives are distinguished syntactically by being able to occur freely either before or after the verb. All other NPs precede the verb.

If core arguments are present in transitive clauses, the canonical word order is S-IO-DO-V, as in (1) and (2). ${ }^{2}$

\footnotetext{
${ }^{2}$ The most detailed account of Kalam SVCs is given by Lane (1991), but other studies include Givón (1990), Pawley (1987, in press), and Pawley and Lane (1998).
} 
(1) Bin kaj-nup piow-ya-k. woman pig-it(OBJ) search-3P-PAST

'The women searched for the pig.'

(2) An np moni ñ-a-k?

who you(OBJ) money give-3S-PAST

'Who gave money to you?'

Departures from this word order are fairly common. For example, a focused Object (animate or inanimate) can precede an animate Subject. When the Object is animate and the Subject is inanimate, the Object usually comes first.

Except for personal pronouns, there is no case-marking on core arguments, peripheral arguments, or adjuncts.

Because zero anaphora is normal for established referents, transitive clauses often occur without an overt Subject or Object NP. Nouns representing Subject and Object often occur without a determiner, especially when the referent is indefinite but specific.

In a sequence of conjoined clauses, the inflected verb in each non-final clause carries a suffix marking two semantic relations to the next verb: relative tense (prior, simultaneous, or prospective) and same or different Subject (switch reference). The final verb is marked for absolute tense and Subject reference.

\subsection{Criteria Defining Subjects, Objects, and Peripheral Arguments}

In clauses that have as their head a transitive verb (either a single root or a complex verb), Subject and Object are distinguished by a number of diagnostics.

\subsubsection{Subject}

Subjects link with the thematic roles of Agent, Effector, Experiencer, and Theme/Patient, probably in that order. I will refer to the highest-ranked role as the Logical Subject. The grammatical (surface) Subject of a verbal clause can be identified using the following formal criteria:

(a) When the Subject is a free pronoun, it selects a pronoun from the Subject class. This class also marks extra-clausal topics as well as possessors that are not grammatical Objects.

(b) Agreement in clauses with a simple verb: the Subject is the NP that is coreferential with the person-number suffix on the main verb. An animacy hierarchy operates in marking number. With human Subjects, the verbal suffix must distinguish singular, dual, or plural. When higher animals are Subjects, the suffix usually distinguishes number, but in some contexts need not do so, using the singular as the default. With lower animal Subjects, the suffix seldom distinguishes number, but may do so. With inanimate Subjects, the verbal suffix is always third person singular. 


\section{Andrew Pawley}

(c) Subjects control verb morphology marking switch reference.

(d) Only Subjects of transitive verbs can be antecedents of the marker key in its reflexive sense (with Agent-Patient verbs) and in its sole participant sense ('by oneself, acting alone') (with Effector or Experiencer Subject verbs and Agent-Theme verbs).

(e) Subjects prefer first position in the clause.

(f) The verbal negative pro-clitic $m a$ - seldom, if ever, precedes Subjects, but occasionally (under some conditions) precedes Objects (when these are a full NP) and Instruments, and often precedes verb adjuncts.

\subsubsection{Object}

Objects link with Experiencer, Patient, Beneficiary, Theme, Place, and Goal. Formal tests for identifying Object NPs (Direct and Indirect Object) are as follows:

(a) When the Object NP is a pronoun, the pronoun is drawn from the Object class.

(b) When an animate Object is represented by a full NP, the NP is optionally followed by an Object pronoun.

(c) The preferred position for Objects is after the Subject and before the verb. Direct Objects normally follow Indirect Objects.

(d) Although it usually follows, the verbal negative pro-clitic $m a$ - can precede a light Object NP other than a pronoun.

Subject and Object are at the very least convenient labels for grammatical relations that are marked by a cluster of morphological and syntactic features. It is true that these morphosyntactic features in most cases mark the same NPs that can be identified by a semantic criterion: the NPs with the highest and second highest ranked thematic role in the clause. However, there are exceptions to this generalization, to be discussed in $\S 2$ and $\S 4$.

\section{Serial Verb Constructions}

\subsection{General Characteristics}

Kalam serial verb constructions (SVCs) provide an elegant and streamlined mechanism for expressing certain kinds of event sequences or overlapping event clusters in a single clause. ${ }^{2}$ The predicate (verb phrase) of an SVC has as its nucleus a verb series, in which one or more bare verb roots precedes an inflected verb root. There is no grammatical limit to the number of verb roots that can 


\section{Argument Structure of Complex Predicates in Kalam}

occur in an SVC. In practice, if we exclude iteration of verb roots to show repetition or continuity, the limit seems to be about ten. The question is: What are the semantic constraints on possible SVCs?

Typically, each verb root in an SVC specifies a separate event in a sequence or an event that overlaps in time with another. The verbs must share the same tense/aspect/mood marking, and this appears only on the final verb. (In schematic representations of verb series, only the final verb is followed by a hyphen to indicate the placement of inflections.) In most types of SVC, the verb series falls under the scope of a single negator and is uttered within a single intonation contour. Some of the main structural features of SVCs are illustrated by (3) and the second clause of (4). Verb roots and their glosses appear in boldface.

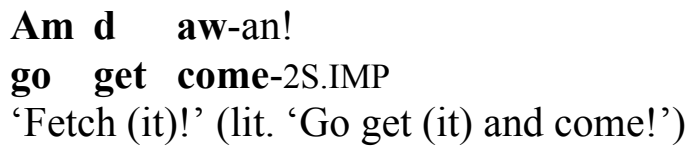

Am d aw-an!

go get come-2S.IMP

'Fetch (it)!' (lit. 'Go get (it) and come!')

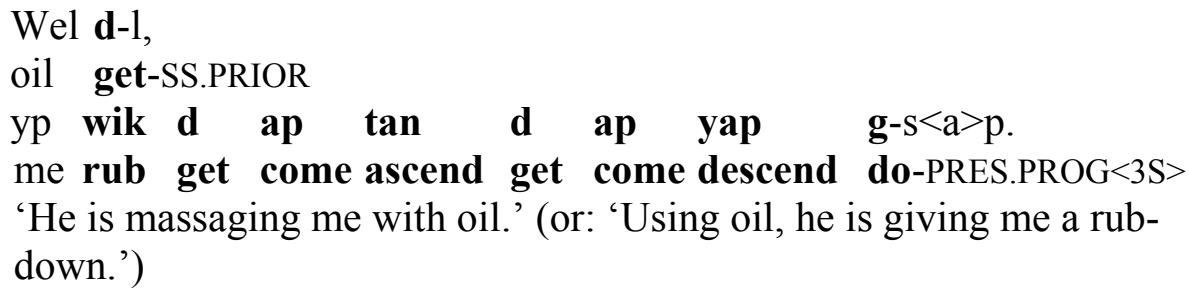

In terms of their semantic and syntactic structure, SVCs can be divided into two main types: compact and narrative SVCs.

\subsection{Compact SVCs}

Compact SVCs express a tight-knit event sequence, one where the constituent events are connected in a causal or close temporal relation. The verb series is also syntactically tight-knit. No arguments can be inserted within it. Locatives can either precede or follow the verb series; all other arguments must precede it. The negative clitic and any adverbial modifiers must precede the entire series. Compact SVCs can be regarded as lexicalized phrases and are often translatable by a single verb in English. Some examples are: $d$ am- (get go) 'take', $d$ ap- (get come) 'bring', ptk am- (fear go) 'flee', ag $\tilde{n}$ - (say transfer) 'tell', ag ask- (say avoid) 'refuse', ag ay- (say stabilise) 'make an appointment, ask to stay', ag $n \eta$ - (say perceive) 'ask', $d n \eta$ - (touch perceive) 'feel', $\tilde{n} b n \eta$ - (consume perceive) 'taste', pk cg-(strike adhere) 'attach, stick on', $d$ ap tan $d$ ap yap- (hold come ascend hold come descend) 'move back and forth'. While most compact SVCs contain two to four verb roots, they are not limited to this range. Thus, the second clause of (4) contains an eight-verb sequence which is arguably a single compact SVC.

The constraints on the marking of grammatical relations in compact SVCs are like single-verb clauses: only one Subject and one Object NP can be expressed. The final verb in the series is always inflected to agree with the Logical Subject 


\section{Andrew Pawley}

(the most prominent thematic role) of the first verb in the series. In most kinds of compact SVC this requires no adjustment in the surface structure: all the verbs share the same Logical Subject. There is, however, one type where this perfect match between Surface Subject and Logical Subject does not hold: resultative or cause-effect SVCs, exemplified in (5).

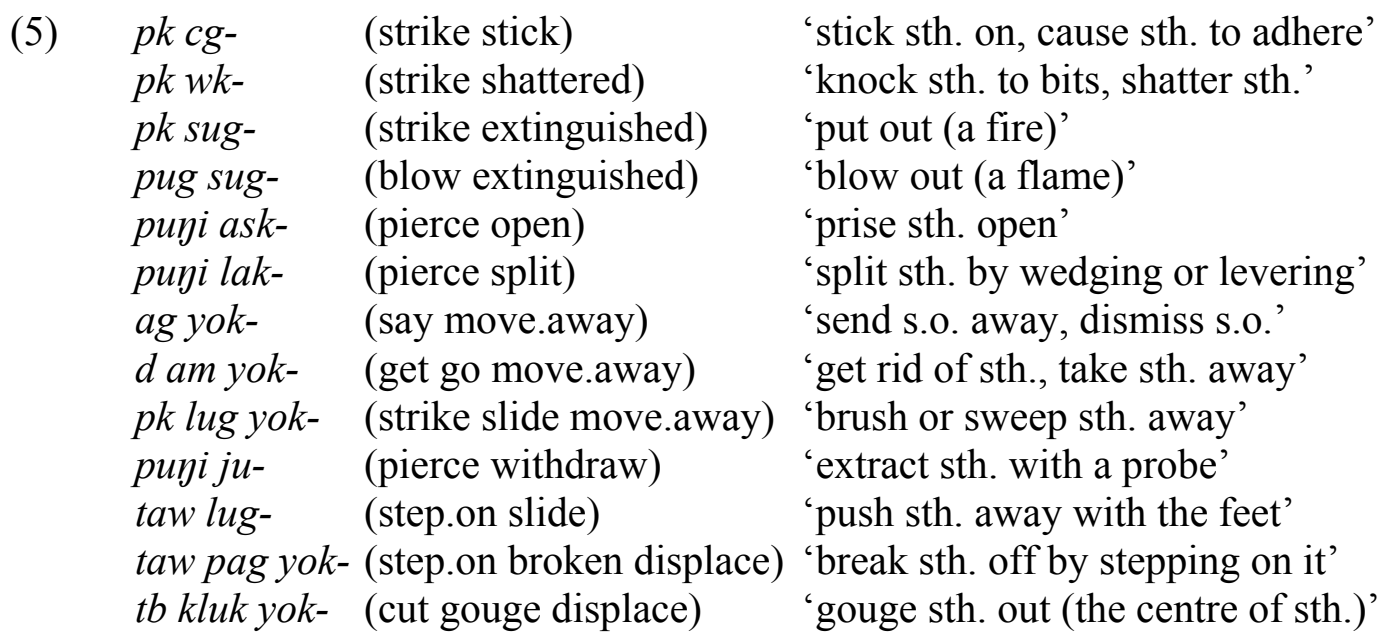

In the simplest case, resultative SVCs contain just two verbs: V1 is transitive and specifies an activity, usually a verb of contact, and V2 is intransitive and specifies a state or movement. The meaning derived from the sequence is that the event denoted by V1 precedes and causes the event denoted by V2, the verb of result. The two verbs share an argument: the Logical Subject of V2, the entity which is in a state or which moves, is also the Patient of V1, the entity which suffers contact. When it comes to marking of Subject, the two verbs behave like a single compound transitive verb. V1 is bare, and V2 carries agreement suffixes referring only to the Logical Subject of V1. That is to say, the SVC adopts the functional structure of the initial, transitive verb, while that of the final, intransitive verb is ignored. This sort of reworking of mismatched lexical argument structures to create a unified structure in the complex resultative predicate is crosslinguistically familiar.

Resultative SVCs are not restricted to two verb roots. More than one verb root can fill the V1 slot, so long as the first verb is transitive and the other roots share with it the same Logical Subject. Examples in (5) above are $d$ am yok (get go move.away) 'get rid of s.th.' and pk lug yok (strike slide move.away) 'brush s.th. away'. More than one verb can fill the V2 slot, so long as all the verb roots are intransitive and share with it the same Logical Subject. An example in (5) is taw pag yok- (step.on broken move.away) 'break s.th. off by stepping on it'.

\subsection{Narrative SVCs}

Narrative SVCs have a much more complex semantic and constituent structure than compact SVCs. They express in formulaic form a sequence of distinct events 


\section{Argument Structure of Complex Predicates in Kalam}

or distinct event clusters, each taking place at different times and in different places, that together make up an episode, a short story.

Narrative SVCs can readily be paraphrased by a chain of clauses. However, a sequence of clauses can be reduced to an SVC only under certain conditions. The clauses must be coordinate; the initial verbs in each clause must share the same Logical Subject and the same Patient (if any); the clauses must report a sequence of events which taken together conforms to Kalam discourse structure conventions for a minimal well-formed report; and the report must be of a familiar class of episodes. For example, a well-formed report on someone's gathering of food or materials should mention four stages: (1) the actor's movement (if any) to the scene of the gathering, (2) the gathering activities, (3) transport of the goods to the scene of disposal (if it occurs), and (4) the disposal activities, such as cooking and eating, distribution, or storage.

Any single stage of a narrative may be represented by an SVC, but to qualify as a narrative SVC, two or more stages of the narrative must be included in the SVC. In example (6), all four stages of a gathering (hunting) episode are represented. In (7) and (8), stages 2-4 are present. Example (9) reports a different kind of episode: escape from confinement, where the component stages are somewhat different. Examples (6)-(9) are all in the Ti dialect.

(6) Basd skop ... am kmn pak d ap ad ñ grandfather distant go animal kill get come cook eat-PAST.HAB.3PL 'Our distant ancestors...used to hunt [lit. go, kill, bring back, cook and eat] game mammals.'

( $k m n$ 'the larger marsupials and arboreal rodents, which men hunt')

...mj bep tk d ap nb okyan yok-l,... leaf plant sever get come place below throw-SS:PRIOR '...having gathered bep leaves and brought and tipped (them) below'

...kuñp ognap tb $\mathbf{d}$ am katp-at okok $\mathbf{l}-1, \ldots$ kuñp(leaves) some cut get go house-area about put-SS:PRIOR '...having gathered kuñp leaves and taken to the house and put (them),...'

(9) Ognap amsu $\tilde{\mathbf{n}} \mathbf{b} \tilde{\mathbf{n}} \mathbf{b}$ mgan okday nb pag jak-1,... sometimes go bite eat eat inside there place break rise.up-SS:PRIOR 'Sometimes, having chewed their way through from inside (the burrow and protective foliage), they break out...'

Each stage in a narrative SVC is represented by a separate predicate phrase, which may be a compact SVC, a single verb, or certain other sequences of verb roots. The predicate phrases show some degree of syntactic independence from one another. Each predicate phrase can take separate adverbial modifiers, for instance, and one sometimes finds that two predicate phrases each has its own 


\section{Andrew Pawley}

Locative adjunct, as in (7). A negative proclitic having scope over the whole SVC may either precede the entire verb series or may precede the final verb. The negative clitic may also negate only the final verb, in which case it immediately precedes that verb.

In spite of their considerable semantic and syntactic complexity, narrative SVCs have a core argument structure that is no more complex than that of compact SVCs. No matter how many predicate phrases the narrative SVC contains, only one Subject NP and one Object NP can appear overtly. Subject agreement is only marked once on the final verb in the construction. The initial verbs of all predicate phrases in the narrative SVC must have the same Logical Subject. If more than one predicate phrase has an (understood or overt) Object, this must be shared.

\section{Verb Adjunct Constructions}

\subsection{General Characteristics}

Verb adjunct constructions (VACs) have the following grammatical and semantic characteristics:

(a) They consist minimally of a verb adjunct plus a verb. Verb adjuncts are an open class of roots and derived words, with several hundred recorded members which occur only as the partner of a verb in a complex predicate. (New members may be recruited to the class by derivational processes and/or by borrowing.)

(b) The verb root is inflected, except when the VAC functions as a non-final serial verb.

(c) They express a single event.

(d) The verb root serves as a classifier. It marks the event as being of a certain general semantic type. The verb adjunct specifies the event as being of a particular subtype of this class or as adding an associated activity to that depicted by the verb root. Only about 20 verbs take part in verb adjunct constructions.

(e) The verb adjunct contributes to the argument structure of the VAC and can be viewed as a co-predicate.

VACs are exemplified by (10)-(12). In these and later examples, the verb adjunct and verb roots appear in boldface, and the whole verb adjunct construction is bounded by square brackets. In an attempt to provide a gloss that is neutral between verb, noun, and adverb, a gerundive gloss (e.g. perching.together, begging, slithering) is used for some verb adjuncts. 
(10) Sawan [guglum ag-ig] $\mathrm{k}-\mathrm{j}<\mathrm{a}>\mathrm{p}$.

Sawan snoring say-SS.SIM sleep-PRES.PROG $<3$ SG $>$

'Sawan is asleep, snoring.'
Yakt omay ok
[gub
g-i]
md-p-it.
bird two those perching.together do-SS.PRIOR stay-PF-3D
'Those two birds are perched together.'

Usually the adjunct and verb root are contiguous, but certain kinds of material may intervene, e.g. locative phrases as in (12), question words as in (13), and modifiers and negators.

(12) Tap tubtub-toktok wad g-i, [dad ms amn-a-k]. things knick-knacks bag do-SS-PRIOR carrying outside go-3S-PAST 'Having put his personal effects in a string bag, he carried them outside.'

(13) Pa-skoy [si etp-nen ag-a-k]?

girl-small crying what-for say-3S-PAST

'Why did the girl cry?'

\subsection{Classes of Verb Adjunct Construction}

VACs can be classified in the first place according to the meaning of the verb adjuncts and the verb (or verbs) they select as co-predicate. Examples follow from each of the three largest classes.

A sizeable class of verb adjuncts selects a verb of locomotion and denotes the manner, direction, or concomitant of the actor's movement. The locomotion verbs that take the widest range of verb adjuncts are am- 'go' and ap- 'come, appear'. Some adjuncts also occur with tag- 'walk about, travel', sayd- 'depart', yap- 'go down, fall', tan- 'go up, climb', ju- 'withdraw', and yok- 'move away, be displaced'. Most verb adjuncts that occur with a verb of locomotion fall into one or another of the semantic categories shown in (14).

a. Manner of actor's movement along a path

$\begin{array}{lll}\text { kleyd am- } & \text { (crawling go) } & \text { 'crawl' } \\ \text { mumlokd am- } & \text { (rolling, tumbling go) } & \text { 'fall over, tumble down' } \\ \text { pug-tkd am- } & \text { (running go) } & \text { 'run' } \\ \text { tawd am- } & \text { (stepping go) } & \text { 'walk' } \\ \text { wald am- } & \text { (sliding, slithering go) } & \text { 'slide, slither' } \\ \text { wayd am- } & \text { (carried.by.water go) } & \text { 'float along' } \\ \text { wyd am- } & \text { (flying go) } & \text { 'fly' }\end{array}$

b. Direction of actor's movement in relation to path or deictic centre gogeb-mageb am- (zigzagging go) 'zigzag along' koday kodoy am- (hither and thither go) 'go hither and thither' 


\section{Andrew Pawley}

$\begin{array}{lll}\begin{array}{l}\text { payd am- } \\ \text { adkd am- }\end{array} & \begin{array}{l}\text { (passing out of sight go) } \\ \text { (turning back, reversing go) }\end{array} & \begin{array}{l}\text { 'pass from view' } \\ \text { 'turn back' } \\ \text { 'go in, enter (an enclo- } \\ \text { (entering go) }\end{array} \\ \begin{array}{ll}\text { tkd } \text { am- } & \text { (crossing over go) }\end{array} & \text { 'cross over (a divide)' }\end{array}$

c. Manner in which a burden is transported or a person/animal is accompanied

\begin{tabular}{|c|c|c|}
\hline dad am- & (carrying go) & 'carry sth.' \\
\hline poyd am- & (guiding go) & $\begin{array}{l}\text { 'guide s.o., take s.o. (to a } \\
\text { place)' }\end{array}$ \\
\hline$s b a m-$ & (brandishing go) & $\begin{array}{l}\text { 'go brandishing sth. (usu- } \\
\text { ally a weapon)' }\end{array}$ \\
\hline kosigd am- & (stacked, piled go) & $\begin{array}{l}\text { 'go carrying sth. on the } \\
\text { back' }\end{array}$ \\
\hline wtsek am- & (chasing go) & 'chase, pursue s.o.' \\
\hline
\end{tabular}

The combined arguments of certain VACs exceed those of any of the constituent predicates. This applies to the VACs in (14c) where each of the verb adjuncts refers to a separate participant. In (15) a verb adjunct poyd 'guiding, leading, accompanying (a person or animal)' is paired with the verb ap- 'come'.

$$
\begin{aligned}
& \text { Yad b tud nup kotp-cn pond ow-n-k. } \\
& \text { I man white him house-our leading } \\
& \text { 'I've brought the white man to our home.' }
\end{aligned}
$$

The adjunct here contributes two participants: a guider (thematic Agent, grammatical Subject) and a guidee (Theme, Object). The verb also contributes two participants: a comer (Agent, Subject) and a destination (Goal, Locative). The guider and the comer are coreferential. Together these two elements create a three-place predicate: guider/comer (Agent, Subject), guidee (Theme, Object), and destination (Goal, Locative).

In (16), the adjunct $d a d$ 'carrying (inanimate object)' is paired with the verb $n$ 'join others on a trip, catch up with someone who has left'.

$$
\begin{aligned}
& \text { Cn np mdak ayn-bogs dad n-ngp-un. } \\
& \text { we you(SG.OBJ) later iron-box carrying join-FUT-1P } \\
& \text { 'We will join you later bringing the metal trunk.' }
\end{aligned}
$$

Together they create a three-place predicate. The adjunct dad contributes a carrier (Agent, Subject) and a burden (Theme, Object). The verb $n$ - contributes a joiner (Actor, Subject) and a joinee (Goal, Object). The carrier and the joiner are coreferential. In (16) the burden is the Direct Object, and the person joined is the Indirect Object. 


\section{Argument Structure of Complex Predicates in Kalam}

There is a large class of verb adjuncts which select the verb ag- 'talk, say, make a sound'. These verb adjuncts almost all refer to kinds of noises. As the sole head of a verb, ag- has both intransitive and transitive uses. Some VACs containing $a g$ - are intransitive, as in (17a). Others, where the adjunct refers to a form of speech, are transitive, as in (17b).

(17) Some VACs containing ag- 'say, make a sound, etc.'

a. intransitive constructions

$\begin{array}{lll}\text { bu ag- } & \text { (exploding say) } & \text { 'explode, burst' } \\ \text { gigu ag- } & \text { (rattling say) } & \text { 'rattle, jingle' } \\ \text { guglak ag- } & \text { (croaking say) } & \text { 'croak' } \\ \text { guglum ag- } & \text { (snoring say) } & \text { 'snore' } \\ \text { mukbel ag } & \text { (belching) say } & \text { 'belch' }\end{array}$

b. transitive constructions

asb ag- (begging say)

paj ag- (taunting say)

asking s.o. for things to be given'

kub ag- (loud.calling say) 'call loudly to s.o.'

kuk ag- (alarm.calling say) 'shout an alarm to s.o.'

Given that ag- out of context is of indeterminate transitivity, it seems that the transitivity of a given VAC string containing this verb is determined by the verb adjunct. In intransitive constructions, the verb adjunct is a single argument predicate referring to a kind of sound that is not speech and so is not (on a normal reading) addressed to anyone. In transitive constructions, the verb adjunct denotes a form of speech which implies an addressee.

The verb that takes the largest number of verb adjuncts is $g$ - 'act, function, do, make, perform', the most general activity and process verb. This verb, too, has both intransitive and transitive uses. VACs that contain $g$ - generally denote either (a) an intentional act, (b) a dynamic event attributed to an inanimate effector, or

(c) a state. Examples are given in (18). Some verb adjunct phrases belong to more than one category, e.g. those in (18c) have a dynamic (and transitive) reading, but some also have a stative reading (18d). Although $g$ - is glossed as 'do' throughout, in some contexts the gloss might equally well be 'make' and in others, 'be'.

(18) Some verb adjuncts occurring with $g-$ 'do'

a. intransitive VACs denoting intentional acts

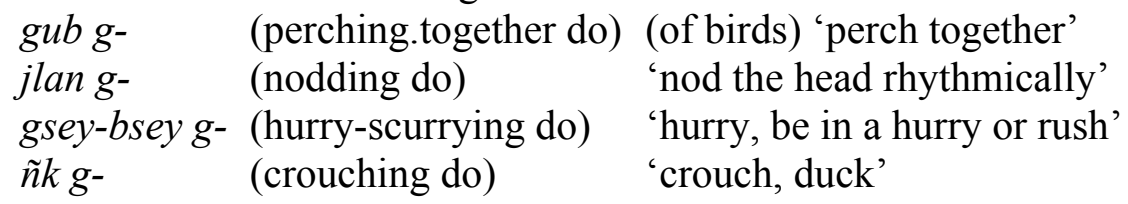


Andrew Pawley

b. transitive VACs denoting intentional acts

$\begin{array}{lll}\text { bl g- } & \text { (abstaining do) } & \text { 'abstain from an activity' } \\ \text { gadal-badal g- } & \text { (criss-crossing do) } & \text { 'lay things criss-cross' } \\ \text { gdey-bdey g- } & \text { (rumple-jumpling do) } & \text { 'do something roughly' } \\ \text { saj g- } & \text { (compensating do) } & \text { 'pay compensation' }\end{array}$

c. transitive VACs denoting events with inanimate Effectors

\begin{tabular}{|c|c|c|}
\hline gtin-gton g- & (ding-donging do) & $\begin{array}{l}\text { 'make a lot of noise, make a } \\
\text { din or racket' }\end{array}$ \\
\hline gley-wley g- & (clitter-clattering do) & $\begin{array}{l}\text { 'rattle, clatter, as bones, } \\
\text { metal objects' }\end{array}$ \\
\hline kawn g- & (swaying do) & 'swing, rock, sway, flap' \\
\hline kopay-mopay g- & (blowing.fiercely do) & $\begin{array}{l}\text { (of storm winds) 'blow } \\
\text { fiercely' }\end{array}$ \\
\hline $\operatorname{lm} g-$ & (shooting do) & (of plant suckers) 'shoot up' \\
\hline wnwn g- & (peeling do) & $\begin{array}{l}\text { (of, e.g., bark) 'peel off, fall } \\
\text { to bits' }\end{array}$ \\
\hline
\end{tabular}

d. intransitive VACs denoting states

\begin{tabular}{|c|c|c|}
\hline gadal-badal g- & (criss-crossing do) & $\begin{array}{l}\text { 'be higgledy-piggledy, } \\
\text { criss-crossed' }\end{array}$ \\
\hline gdey-bdey g- & (rumple-dumpling do) & 'be in disarray' \\
\hline gogeb-mageb g- & (twisted do) & 'be twisted, crooked' \\
\hline gutgat g- & (drenched do) & 'be drenched and cold' \\
\hline kolkol g- & (tangled do) & 'be tangled' \\
\hline$j l g-$ & (loose-fitting do) & 'be loose, loose-fitting' \\
\hline
\end{tabular}

As with $a g$-, it seems that the verb adjunct determines the transitivity of VACs containing $g-$.

\subsection{Are Verb Adjuncts a Distinct Part of Speech?}

The verb adjunct category is problematic. Although some common features distinguish this class from other parts of speech, its members are far from homogeneous in semantic type or syntactic behavior. In meaning, some verb adjuncts resemble prototypical verbs, while others resemble nouns, adjectives, or adverbs. In their grammatical behavior, verb adjuncts are sharply distinct from verbs. Verb adjuncts cannot take verbal inflections and cannot occur alone as the head of a predicate phrase. They differ from adjectives, which can modify nouns.

Verb adjuncts resemble adverbs in being modifiers of verbs. However, they differ from typical adverbs in several respects: (a) an adverb can combine with many different verb roots whereas a verb adjunct can combine only with a very restricted set; (b) adding an adjunct in some cases creates a complex predicate with a different argument structure from the verb root alone, whereas adverbial modifiers do not affect the valency of the predicate phrase; (c) adjuncts can take 


\section{Argument Structure of Complex Predicates in Kalam}

at least some adjectival modifiers but adverbs cannot; (d) adverbs modify the verb in a general sense and in a graded way, e.g. for speed, intensity, or purposefulness, whereas verb adjuncts typically specify a particular kind of action, process, or state that is a subtype of the category of event denoted by the verb; and (e) whereas adverbs may modify the whole VP, the scope of verb adjuncts is restricted to the verb.

Canonical verb adjuncts differ from nouns in that they are cannot be possessed or quantified and cannot be questioned, topicalized, or relativized. Some verb adjuncts resemble nouns in that they can be modified by intensifying adjectives (such as yob 'big, loud', koyay 'many', tmey 'bad, intensifier', and naban 'very') and in that they represent a propositional participant of a performance verb such as ag- 'say' and $g_{-}$'do', i.e. the adjunct represents something said or done. One has to say something, and one has to do something. Thus, in (11), gub 'perching together' is the action performed, and in (13), si 'crying' is the sound that is uttered even though neither verb adjunct has strong claims to be the direct object. In these respects, they resemble incorporated objects in many languages, some coverbs in Jaminjung (Schultze-Berndt 2000:189-190), and to some extent nominals in some $\mathrm{N}+\mathrm{V}$ complex predicates in Hindi which serve both as arguments and as predicates (Mohanan 1997).

Foley (1986:117-119) would extend the class of verb adjunct constructions in Kalam to include sequences where the 'adjunct' is a typical noun which occurs before a verb to form a conventional expression, e.g. $w d n n \eta$ - (eye perceive) 'see',

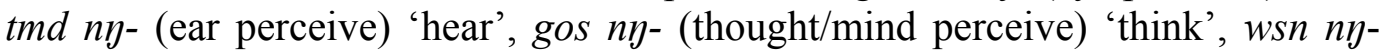
(dream perceive) 'dream', mnm ag- (speech say) 'speak', kmap ag- (song say) 'sing'. In such expressions the nouns are non-referential, so are not arguments, and can be viewed as incorporated in the predicate phrase. (Nouns occurring in such sequences are referred to in Pawley et al. (2000) as 'quasi verb adjuncts', in contrast to 'true verb adjuncts'.) A problem is that these nouns have different combinational privileges from true verb adjuncts. Unlike verb adjuncts, the nouns can take determiners, quantifiers, and possessors, and they can be arguments. Thus, mnm 'speech' and kmap 'song' can be the Direct Object of ag- 'say, utter, make a sound' and $w d n$ 'eye' and tmd 'ear' can be treated as Locatives or Instruments (the place or means of perception) of $n \eta$ - 'perceive'.

Adopting a constructional approach might allow us to have the best of both worlds. Constructions where an incorporated non-referential noun modifies a verb show a strong family resemblance to, or formal overlap with, constructions where a non-referential verb adjunct modifies a verb. This family resemblance might be formally represented by positing a single major construction type which subsumes both verb adjuncts and incorporated nouns, while also recognizing that there are a number of subtypes in this family. The fact that these nouns can also occur as Direct Objects or Instruments would be captured by recognizing another set of constructions. 


\section{Andrew Pawley}

\section{Involuntary Experience Constructions 4.1. General Characteristics}

It is the third group of constructions, involuntary experience constructions (IECs), that is hardest to analyze. ${ }^{3}$ IECs denote uncontrolled bodily or mental events, such as bleeding, sweating, shivering, feeling sick, hungry, or angry, needing to vomit, being overcome by laughter, or having boils, warts, or pimples. It is well-known that languages vary a good deal in how they describe such events, in particular in the grammatical status given to the Experiencer and to the constituent (be it verbal or nominal) denoting the bodily or mental processes.

Unlike English, Kalam expresses many uncontrolled bodily and mental experiences by transitive clauses, albeit non-typical ones. It is transitive IECs that we are concerned with here. These clauses require at least two nominal participants. One participant, which I will refer to by the cover term 'Condition', refers to a bodily or mental process or state that affects the Experiencer. The other represents either an Experiencer NP or a Location NP. The Location NP refers to the body part that is the locus of the Condition. It is usually possessed, or the possessor is recoverable from the context. When the Experiencer consists of a pronoun, it is always accusative. Likewise, when a body part nominal in an IEC is possessed, it is always possessed by an accusative pronoun.

The verb (which may be a single verb or a compact SVC) marks a relation between these participants, specifically the manner in which the Condition manifests itself in or affects the Experiencer or body part. For example, a Condition may 'appear', 'form', 'fall', 'rise', 'grow', or 'act' on, or it may 'pierce' or 'eat' the Experiencer. The usual order of constituents is LOCATION EXPERIENCER CONDITION VERB, as in (19)-(24). However, in some kinds of IECs, the three preverbal constituents can occur in any order. In (19-24) and later examples, the Condition nominal and the verb root(s) are shown in boldface.

$$
\begin{array}{lll}
\mathrm{Np} & \text { wsb } & \text { jak-s }<\mathrm{a}>\mathrm{p} . \\
\text { you.S(OBJ) } & \text { sweat } & \text { rise-PRES.PROG }<3 \mathrm{~S}>
\end{array}
$$

'You are starting to sweat.'

$$
\begin{array}{lll}
\text { Nup } & \text { suk } & \text { ow-p. } \\
\text { him } & \text { laughter } & \text { come-PF-3S }
\end{array}
$$

'He is about to laugh.'/'He feels like laughing.'

$$
\begin{array}{lll}
\text { Yp } & \text { ydk } & \text { g-p. } \\
\text { me } & \text { good-tasting } & \text { do-PF.3S }
\end{array}
$$

'It tastes good to me.'

\footnotetext{
${ }^{3}$ A fuller account of Kalam IECs is given in Pawley et al. (2000). The only other detailed treatment of IECs in a TNG language that I am aware of is a very thorough analysis of Amele by Roberts (2001). Amele IECs work somewhat differently from those of Kalam.
} 
$\begin{array}{llll}\begin{array}{l}\text { Kud=yp } \\ \text { back=my(OBJ) }\end{array} & \text { ak } & \text { yuwt } & \text { g-s }<\text { a }>\text { p. } \\ \text { the } & \text { pain } & \text { do-PRES.PROG }<3 \mathrm{~S}>\end{array}$

'It is my back that is hurting.'

(23) Jun=np yuwt tmey g-p.

head=her pain bad do-PF-3S

'She has a bad headache.'/'Her head is hurting badly.'
Tglm-wagn=yp
puni $\quad \tilde{\mathbf{n}} \mathbf{b}-\mathrm{s}<\mathrm{a}>\mathrm{p}$.
ribs-base $=$ my (OBJ)
pierce eat-PRES.PROG $<3 \mathrm{~S}>$.
'There's a sharp pain in my ribcage'.

The grammatical status of the Experiencer and Location nominals in IECs is clear. Given that they select an accusative pronoun, these must be regarded as Objects of a sort. They cannot be the Subject, for three main reasons. First, the Experiencer is represented by a pronoun from the Object set. Second, the personnumber suffix on the verb does not agree with the Experiencer NP; the verb is always marked for third person singular. Third, in this class of constructions, switch reference, a syntactic process sensitive to Subject identity or change across clauses, cannot be triggered by the Experiencer or Location NP.

Some IECs contain separate Experiencer and (non-possessed) Location NPs, as in (25). This co-occurrence requires a distinction to be made in such constructions between two kinds of Objects, call them 'Direct' and 'Locative' Objects.

$$
\begin{aligned}
& \text { Yp mablep kogm ay-a-k. } \\
& \text { me wart(s) knee form-3S-PAST } \\
& \text { 'I had a wart/warts on the knee.' (lit. 'Wart(s) formed on me on the knee.') }
\end{aligned}
$$

\subsection{What Is the Status of the Condition Nominal (and Other Questions)?}

Various questions arise in the analysis of IECs. What is the grammatical role played by the Condition nominal? Is it the Subject? Is it a kind of verb adjunct, and so part of a complex predicate? Or does it contrive to be both verb adjunct and incorporated Subject? Do IECs have a Subject at all? Is a uniform analysis of IECs possible, or is this a disparate class? Another question concerns the source of the argument structure of IECs. Is this projected by the verb, or does it belong to the construction as a whole?

Foley (1986), writing about Kalam IECs, and Donohue (2005), writing about IECs in another TNG language, Lani, regard the Condition nominal as a kind of verb adjunct, forming a complex predicate together with the verb. On this analysis, Kalam IECs would have no Subject other than a dummy representation by a thirdperson singular suffix on the verb. It is true that all Condition nominals resemble verb adjuncts and differ from typical Subjects in that they typically occur immediately before the verb (rather than in canonical Subject position verb-initially). It is also true that some Condition nouns resemble verb adjuncts in that they co- 


\section{Andrew Pawley}

occur only with a single verb or a very few verbs, and in that they are nonreferential, or at least cannot take a determiner or quantifier or occur as Direct Objects, topics, or heads of relative clauses.

However, Condition nominals are not a homogeneous class. Some Condition nominals score highly on standard tests for nouniness $(§ 1.1)$ and show very few verb adjunct properties ( $\$ 3.1)$. Others (call them 'atypical' nouns) score rather poorly on tests for nouniness and show more verb adjunct properties. Both sets of nouns meet the most important tests for subjecthood that are applicable to IECs in all constructions they occur in.

Unfortunately, two of the most reliable tests for identifying Subjects, namely (i) selection of a nominative pronoun, and (ii) Subject-verb agreement, are indeterminate for IECs. The pronominal test does not work because Condition NPs (unlike Experiencers) cannot be pronominalized in this context. The Subject agreement test is indeterminate because when the Subject NP is inanimate, the verb agreement suffix is invariably third person singular, regardless of whether the NP is singular, dual, or plural.

We are left with the four other morphosyntactic tests mentioned in $\S 1.3$ and with a semantic criterion: position in the hierarchy of thematic roles.

\subsubsection{Switch Reference as a Test of Subjecthood}

It was noted earlier that verbs that belong to coordinate clauses carry suffixes marking change of Subject (DS) or same Subject (SS). Control of switch reference is the most powerful of the available grammatical tests for subjecthood in IECs.

All Condition nominals appear to be able to trigger switch reference. The complex sentences (26) and (27) each consist of a pair of IECs. In (26), the first clause describes a bodily process which precedes (and, by implication, causes) a sensation described in the second clause. A change of Subject is signalled in the first clause. The only candidates for Subject are the Condition nominals, denoting a boil and pain, respectively.

$$
\begin{array}{llllll}
\text { Syl } & \mathrm{nn}=\mathrm{yp} & \text { ay-e-k, } & \text { (yp) } & \text { yuwt } & \text { g-p. } \\
\text { boil } & \text { arm=my } & \text { form-DS.PRIOR-3S } & \text { (me) } & \text { pain } & \text { do-PF.3S }
\end{array}
$$

'A boil has formed on my arm and it's painful (to me).

In (27), the two clauses describe simultaneous bodily processes: a growling stomach and being hungry. The first condition is, by implication, a symptom or consequence of the second. Again, the only candidates for Subject are the Condition nominals.

\footnotetext{
Sb-wt=cnp gullg ag-a-kny, cnp yuan g-s-a-p. innards $=$ our rumbling say-3S-DS.SIM us hunger act-PRES.PROG $<3 \mathrm{~S}>$ 'When our stomachs are growling, we are hungry.' ('When rumblings sound in our innards, hunger has acted on us.')
} 


\section{Argument Structure of Complex Predicates in Kalam}

In the next example, the two clauses share the same Experiencer, but not the same Subject. The first clause is an IEC with an Experiencer Object and describes an illness (tap) that affected the Experiencer. The second clause is not an IEC. Here the Experiencer is the Subject, and there is no Condition nominal; instead, the verb sequence describes the condition: remaining indisposed (unable to work) for a period. The only nominal available to be Subject in the IEC clause is tap.

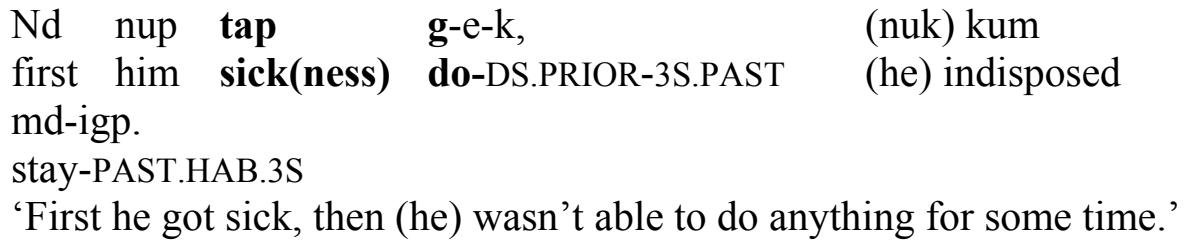

In the next example, the first clause has an Agent Subject, the eater. In the second clause, an IEC depicts a subsequent event in which the eater is the (understood) Object, experiencing pleasure. The only available candidate for Subject in the second clause is tep 'good, pleasure, pleased'.

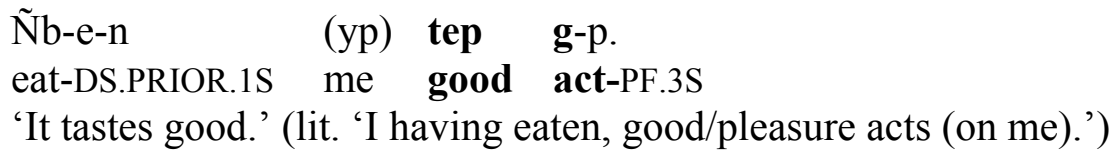

There is a qualification to make about the switch reference test. In some circumstances a verb can be marked for same-Subject-as-next-clause even when the following clause has a different referent as Subject. This option is available when the first clause depicts an event with an Effector (inanimate cause) as Subject and when the following clause depicts a similar class of event which is regarded as a natural consequence of the first, e.g. lightning flashes, then thunder sounds. Examples (30)-(31) illustrate this point. Each contains a pair of IECs containing different Condition nominals, and the second IEC describes an event consequent upon the preceding event.

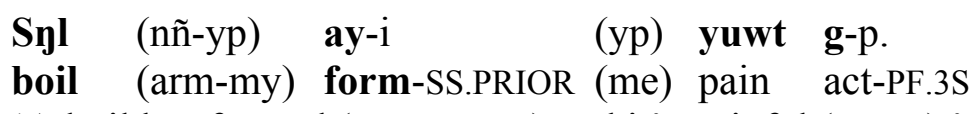

'A boil has formed (on my arm) and it's painful (to me).'

$\begin{array}{llllll}\text { Yp } & \text { wog } & \text { yuwt-bt } & \text { g-i, } & \text { yp } & \text { ytuk g-p. } \\ \text { me } & \text { work exhaustion } & \text { do-SS.PRIOR } & \text { me } & \text { lethargy act-PF.3S }\end{array}$ 'I'm worn out from working.' (lit. 'Work weariness having acted on me, lethargy has affected me.')

However, marking for different subject is always an option in these circumstances (with no change in meaning), so the switch reference test remains valid. 


\section{Andrew Pawley}

\subsubsection{Coreference with Reflexive/Sole Participant Marker key}

It was noted in $\S 1.3$ that only Subjects can be the antecedent of key when this word marks reflexive (with Agent-Patient verbs) or refers to the sole participant in an event (Effector or Experiencer Subject and Agent-Theme verbs). The Experiencer in an IEC cannot be coreferential with key in either of these senses. However, the Condition nominal behaves like other verbs with Effector Subjects:

$$
\begin{array}{llll}
\text { Soy mebi } & \text { key } & \text { ay-p. } \\
\text { ulcer } & \text { here } & \text { by.itself } & \text { form.PF.3S }
\end{array}
$$

'This sore here formed by itself.' (e.g. there was no prior wound)

\subsubsection{Other Tests}

The other two morphosyntactic tests for subjecthood (preferred order of major constituents in the clause and placement of the negative pro-clitic $\mathrm{ma}^{-}$) are not worth a great deal. In IECs, the Condition nominal can occur clause-initially in the preferred position for Subjects, as in (33a). However, its preferred position is immediately before the verb, following the Object (33b), and in this respect Condition nominals resemble verb adjuncts. But while this is an unusual position for animate Subjects, it is fairly common for an inanimate Subject (e.g. an arrow) to follow an animate Object (e.g. a person wounded by the arrow).
a. Yuan yp g-p.
hunger me do-PF.3S
'I am (feeling) hungry.'
b. Yp yuan g-p.
me hunger do-PF.3S
'I am (feeling) hungry.'

The negative proclitic normally attaches to the verb and follows the Condition NP. However, it can precede it.
a. Yp yuan $m a=$ g-p.
me hungry not=do-PF.3S
'I am not (feeling) hungry.'
b. Yp ma=yuan g-p.
me not=hunger do-PF.3S
'I am not (feeling) hungry.'

The order in (34b), which parallels the fairly frequent occurrence of ma-before verb adjuncts, might be taken as evidence that the Condition nominal is not a Subject, but is part of a verb phrase constituent consisting of the verb plus verb adjunct (if any) plus non-Subject arguments. However, the negative clitic is rather 


\section{Argument Structure of Complex Predicates in Kalam}

flexible in its placement. It is occasionally found before canonical Direct Objects (if they are not pronouns) and before Instruments, and some informants even accept its placement before a Subject when this is an inanimate nominal (e.g. yakam 'arrow') that is placed immediately before a verb.

Appealing to the ranking of thematic roles is somewhat unsatisfactory insofar as it invites circularity. The ranking of roles is determined in the first place by which nominals one regards as being a Subject or not a Subject, and so on, in particular cases. Nevertheless, there are clear cases, and these can be used as a reference point when dealing with unclear cases.

\subsubsection{Cases Where the Condition Nominal Is a Canonical Noun}

Test for nouniness allow us to gauge where particular Condition nouns stand on the scale of normal to peculiar Subjects. In some types of IEC, the Condition nominal is a normal noun and behaves as a normal Subject nominal apart from a preference for occurring next to the verb. These are chiefly Condition nominals that refer to a tangible, substantial bodily condition. A selection of cases follows.

(a) Stable visible conditions marked by $a y$ - 'put, form, stabilise, become'

Condition nouns denoting a stable, visible condition typically occur with the verb ay- 'put, form, stabilize, become, turn into', often with a body part nominal specified. Examples of such Condition nouns are kñowy 'birthmark', magi-wt 'scar', sbek 'pimple', slañ 'scab', syl 'boil, abscess', soy 'sore, ulcer', tmd sb 'earwax', and wdn-sgalb 'sleep (dry secretion in eyes)'. These are canonical nouns which can take determiners, quantifiers, and possessors and can occur as Objects, topics, or heads of relative clauses. In (35), syl 'boil' takes a determiner and is modified by two adjectives, the second a quantifier.

$$
\begin{aligned}
& \text { Nup syl yob omyal ak alkjon ay-a-k. } \\
& \text { him boil big two those armpit form-3S-PAST } \\
& \text { 'He had those two large boils in the armpit.' } \\
& \text { (lit. 'Those two large boils formed on him in the armpit.') }
\end{aligned}
$$

It is noteworthy that in this type of construction the verb $a y$-does not carry its most common sense 'put', but has a sense roughly translatable as 'be in a stable condition or form'. That is to say, sense selection in the verb in this case is attributable to occurrence in a particular kind of IEC.

(b) Onset of a condition or process associated with a bodily product, marked by ap- 'come, appear'

The verb ap- 'come, appear' occurs both with Condition nouns that refer to stationary, visible bodily conditions (such as those that occur with $a y$-), but also with visible bodily products that are watery and mobile such as $l k a \tilde{n}$ 'blood', si-ñg 
suk 'laughter', and wsn 'sleep'. In such expressions, the use of ap- indicates that the Experiencer is starting to feel or be affected by the condition (the onset of cramp, wanting to sleep or to laugh, as in (20)).

The largest class of atypical nouns, however, occurs with $g$ - 'happen, do, make, act or work on, affect something'. This verb combines with verb adjuncts, quasi-adjuncts, and adjectives representing several types of Condition. Prominent among these are terms for sensations (or processes that involve sensations) or feelings, e.g. naby 'shame', yuan 'hunger', yuwt 'pain', yuwt-bt 'exhaustion', ytuk 'lethargy', pboy 'heat, hot', ygen 'cold (from wind)', takl 'cold' (general)', $\mathrm{km}$ 'bitter', $y d k$ 'good taste, tasty', slk '(i) hot-tasting, pungent, (ii) itching', ñekñek 'hiccup', jlken 'cough, head cold', tap 'sick, sickness', kajknm 'wince'. Names of sensations are not as nouny as most other Condition nouns. However, they can be modified for manner or intensity, as in (40)-(42).

Yp takl tmey g-p. me cold awfully act-PF.3S

'I am terribly cold.'

Yp naby yob g-a-k. me shame big do-3S-PAST

'I was very ashamed/shy/embarrassed.'

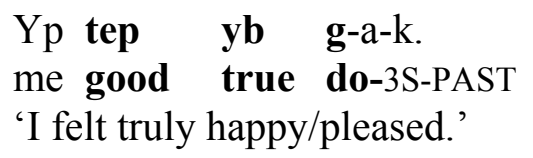

It is doubtful whether most, if any, Condition nouns denoting sensations and other invisible processes can be possessed. When an accusative pronoun immediately follows such a noun, e.g. (43), it is likely that the pronoun is not the possessor, but belongs to a separate phrase representing the Experiencer and is synonymous with (44):

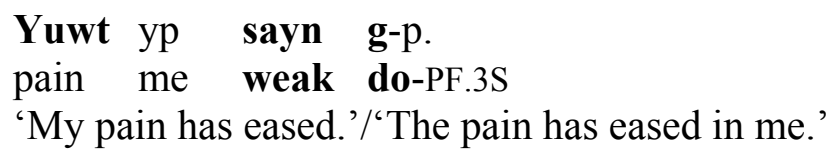

$$
\begin{aligned}
& \text { Yp yuwt sayn g-p. } \\
& \text { me me weak do-PF.3S } \\
& \text { 'The pain has eased in me.' }
\end{aligned}
$$

\subsubsection{Clauses Where There Are Two Condition Nominals}

Some IEC clauses contain two Condition nominals, neither of which is possessed. In such cases, the second nominal denotes a sensation or other invisible process or condition. 


\section{Andrew Pawley}

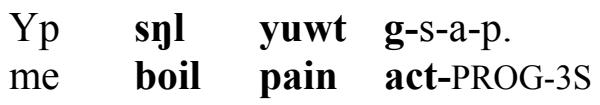

'A boil is causing me pain.'

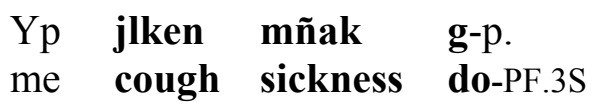

'I am a bit sick with a cough.'

What is the structure of such sequences? Three different interpretations suggest themselves. One is that one nominal modifies the other, forming a complex NP which is the Subject. In (45), this would require syl yuan to be interpreted as '(a) painful boil' and in (46), jlken mñak as '(a) cough sickness' (cf. mñak 'non-serious, short-lived sickness'). There is, however, clear evidence against this interpretation, namely that the Experiencer can intervene between the two Condition nominals in IECs and that in neither case do these two nominals form an acceptable complex noun phrase in other contexts.

A second and more plausible interpretation - one that accords with my understanding of what (45) and (46) mean-would treat the first Condition nominal as specifying the cause of the Experiencer's pain or sickness, answering the question 'Why are you in pain/sick?' or 'What is causing you to be in pain/sick?'. Such questions are normally asked by preposing the interrogative etp-nen 'why?, what for?' to the single Condition nominal, as in (47a). The cause of a bodily condition may be named as another, more specific ailment, or it may be named, for instance, as a craving for something, as in (47b).
a. $\mathrm{Np}$
etp-nen yuan
what-for hunger
g-p?
you(OBJ) what-for hunger act-PF.3S
'What are you hungry for?'
b. Yp pis-nen yuan g-p.
me tinned.fish-for hunger act-PF.3S
'I'm hungry for tinned fish.'

In this analysis, the first Condition nominal is an Adjunct, a peripheral argument. The second Conditional nominal retains its claims to be (an atypical) Subject. However, unlike nouns that denote tangible conditions and bodily products, nouns denoting intangible processes and states must remain close to the verb in constructions with two Condition nouns. The order of the Condition nominals cannot be reversed, i.e. the intangible process/state nominal cannot precede the tangible condition nominal. And whereas a body part nominal can intervene between visible Condition noun and verb, as in (25), (30), and (35), none can occur between invisible process/state noun and verb.

This distributional constraint is consistent with the third possible interpretation of IECs with two Condition nominals, namely that the nominal closest to the 


\section{Argument Structure of Complex Predicates in Kalam}

verb functions both as a Subject and as a verb adjunct. In terms of argument structure, it behaves like the Subject because it controls switch reference and fills the Subject slot. But in terms of predicate structure, Condition nouns denoting an intangible process/state behave rather like verb adjuncts, lacking many of the combinatorial privileges of typical nouns, co-occurring with a very small range of verbs, and preferring a position close to the verb.

\subsection{Residual Problems}

My brief discussion of transitive IECs has left many details unexplored. In particular, the status of certain Condition nominals remains problematic. The Condition nominal is the strongest candidate for Subject of an IEC because it controls switch reference (and therefore we can also assume it controls Subject agreement, which is formally indeterminate). However, Conditional nominals are a very mixed bag. Some (chiefly those denoting tangible conditions) behave like canonical nouns, and others behave more like verb adjuncts.

Mohanan (1997) has proposed that one class of N+V sequences in Hindi require multidimensional representations to reflect a mismatch between argument structure and grammatical category structure. Similarly, in Kalam IECs there are indications that some Condition nouns manage at the same time to be Subjects, in the domain of argument structure, and verb adjuncts, in the domain of constituent structure. However, these nouns behave differently from true verb adjuncts ( $\$ 3.3)$ in a number of respects and we have not established that they form a complex predicate with the verb. Further exploration of these matters will have to left for another occasion.

\section{Touching on the Virtues of a Construction-Based Treatment of Kalam Complex Predicates}

The merits of a constructionist treatment of the argument structure of these three types of kinds of construction have been touched on in passing at various points in the discussion. Evidence was noted that the different heads in a complex predicate jointly determine the argument structure of the clause. Another point in favor of the constructionist position is that Kalam verb roots out of context cannot be fully specified for the range of semantic and grammatical properties they show in different contexts. Most common verbs have a number of different senses, each with their own grammatical subcategorizations, and these particularities of sense and subcategorization are associated with particular constructions. For example, although all verbs in IECs occur with two core arguments, some of these verbs are intransitive in other constructions, or at least cannot take an Object which is an Experiencer. This is the case, for instance, with ap- 'come, appear', yap- 'fall', and jak- 'stand, rise'. These verbs of motion 'take on transitivity' by virtue of occurring in a particular form-meaning constructional pairing in which the Subject slot is filled by a Condition nominal and the Object slot by an Experiencer, and the role of the verb is to indicate roughly that the 'Condition affects/manifests itself in the Experiencer'. 


\section{Andrew Pawley}

\section{References}

Alsina, Alex, Joan Bresnan, and Peter Sells, eds. 1997. Complex Predicates. Stanford: Center for the Study of Language and Information.

Donohue, Mark. 2005. Configurationality in the Languages of New Guinea. Australian Journal of Linguistics 25(2):181-218.

Foley, William. 1986. The Papuan Languages of New Guinea. Cambridge: Cambridge University Press.

Goldberg, Adele E. 1995. Constructions: A Construction Grammar Approach to Argument Structure. Chicago: University of Chicago Press.

Lane, Jonathan. 1991. Serial Verb Constructions in Kalam. M.A. thesis, University of Auckland. [in press in Pacific Linguistics]

Mohanan, Tara. 1997. Multidimensionality of Representation: NV Complex Predicates in Hindi. In Alsina et al., eds., 431-471.

Pawley, Andrew. 1987. Encoding Events in Kalam and English: Different Logics for Reporting Experience. In Russell S. Tomlin, ed., Coherence and Grounding in Discourse, 329-360. Amsterdam: John Benjamins.

Pawley, Andrew. In press. Compact versus Serial Verb Constructions in Kalam. In Gunter Senft, ed., Serial Verb Constructions in Austronesian and Papuan Languages. Canberra: Pacific Linguistics.

Pawley, Andrew, and Jonathan Lane. 1998. From Event Sequence to Grammar: Serial Verb Constructions in Kalam. In Anna Siewierska and Jae Jung Song, eds., Case Typology and Grammar, 201-227. Amsterdam: John Benjamins.

Pawley, Andrew, Simon Peter Gi, Ian Saem Majnep, and John Kias. 2000. Hunger Acts on Me: The Grammar and Semantics of Bodily and Mental Process Expressions in Kalam. In Videa P. de Guzman and Byron W. Bender, eds., Grammatical Analysis: Studies in Honor of Stanley Starosta, 153-185. Honolulu: University of Hawai'i Press.

Roberts, John. 2001. Impersonal Constructions in Amele. In Alexandra Y. Aikhenvald, R.M.W. Dixon, and Masayuki Onishi, eds., Non-Canonical Marking of Subjects and Objects, 201-250. Amsterdam: John Benjamins.

Schultze-Berndt, Eva. 2000. Simple and Complex Verbs in Jaminjung. Ph.D. diss., Nijmegen: MPI Series in Psycholinguistics.

Andrew Pawley

Department of Linguistics, RSPAS

Australian National University

Canberra, ACT 200

Australia

andrew.pawley@anu.edu.au 